\title{
An in-vitro morphological study of Q-switched neodymium/YAG laser trabeculotomy
}

\author{
SHALINI VENKATESH', WILLIAM R LEE', SHEENA GUTHRIE, ${ }^{2}$ \\ FRANCIS R CRUICKSHANK, ' WALLACE S FOULDS,' ROBERT J QUIGLEY,' \\ AND RAYMOND T BAILEY ${ }^{2}$
}

From the 'Tennent Institute of Ophthalmology, University of Glasgow, Glasgow, and the ${ }^{2}$ Department of Pure and Applied Chemistry, University of Strathclyde, Glasgow.

SUMMARY Laser trabeculotomies produced by directing a pulsed neodymium/YAG laser beam at specimens of human anterior chamber angle obtained post mortem or after enucleation were studied by light microscopy and by scanning and transmission electron microscopy to assess the dimensions of the openings created in the trabecular meshwork, their penetrance to the canal of Schlemm, and the extent or absence of laser induced cellular damage in immediately adjacent tissue. A pulse duration of 40-50 ns at energy levels of around $30 \mathrm{~mJ}$ was used and the laser cavity carefully tuned to give a Gaussian spatial mode pattern. Openings in the trabecular meshwork typically of $100 \mu \mathrm{m}$ in diameter and penetrating through to the canal of Schlemm could be regularly created with only minimal damage to adjacent tissue as judged by transmission electron microscopy. The information so gained may be useful in determining the parameters required for successful laser trabeculotomy as a treatment for primary open-angle glaucoma.

A Q-switched neodymium/YAG laser system has been developed with the intention of performing internal laser trabeculotomies as a treatment for primary open-angle glaucoma. The ultimate aim of such a treatment would be to create dimensionally controlled, precisely positioned channels through the diseased and hyalinised meshwork without inducing a tissue repair response in the adjacent trabecular tissue or within the lumen of Schlemm's canal.

This report describes in-vitro experiments using the $\mathrm{Nd} / \mathrm{YAG}$ system on samples of the chamber angle from human eyes, obtained post mortem or after surgical enucleation. Some samples were fixed in glutaraldehyde before the laser treatment so that control over tissue autolysis was achieved; others were not fixed, in order to assess any alteration of the response to the laser pulses in the absence of membrane stabilisation by the fixative.

The laser operating parameters were chosen after preliminary experiments ${ }^{1}$ had indicated the appropriate levels required to produce channels of suitable dimensions (c. $100 \mu \mathrm{m}$ diameter). The

Correspondence to Dr S Venkatesh, Department of Electronic and Electrical Engineering, University College London, Torrington Place, London WC1E 7JE. effects of the laser pulses were studied initially by scanning electron microscopy, as this was a relatively quick way to detect the presence and location of laser holes and to study their configuration and dimensions.

Selected tissue samples were then retrieved for resin embedding for light and transmission electron microscopy in order to study the laser damage at a cellular level and to reinforce the dimensional data obtained by scanning electron microscopy.

\section{Materials and methods}

LASER OUTPUT AND DELIVERY SYSTEM

The laser system used was the Hyper YAG 2000 produced by $\mathrm{J}$ K Lasers Ltd. It was operated at its fundamental wavelength of $1.06 \mu \mathrm{m}$. The Qswitched pulse durations were between 40 and $50 \mathrm{ns,}$ as measured by a fast photodiode detector (Centronic APD 05 4R). Fig. 1a shows the temporal intensity profile of a typical pulse.

The laser output was channelled into its fundamental transverse mode, which offered two advantages: (1) the theoretical limit for the focused beam diameter is smaller than for other modes, and (2) the 

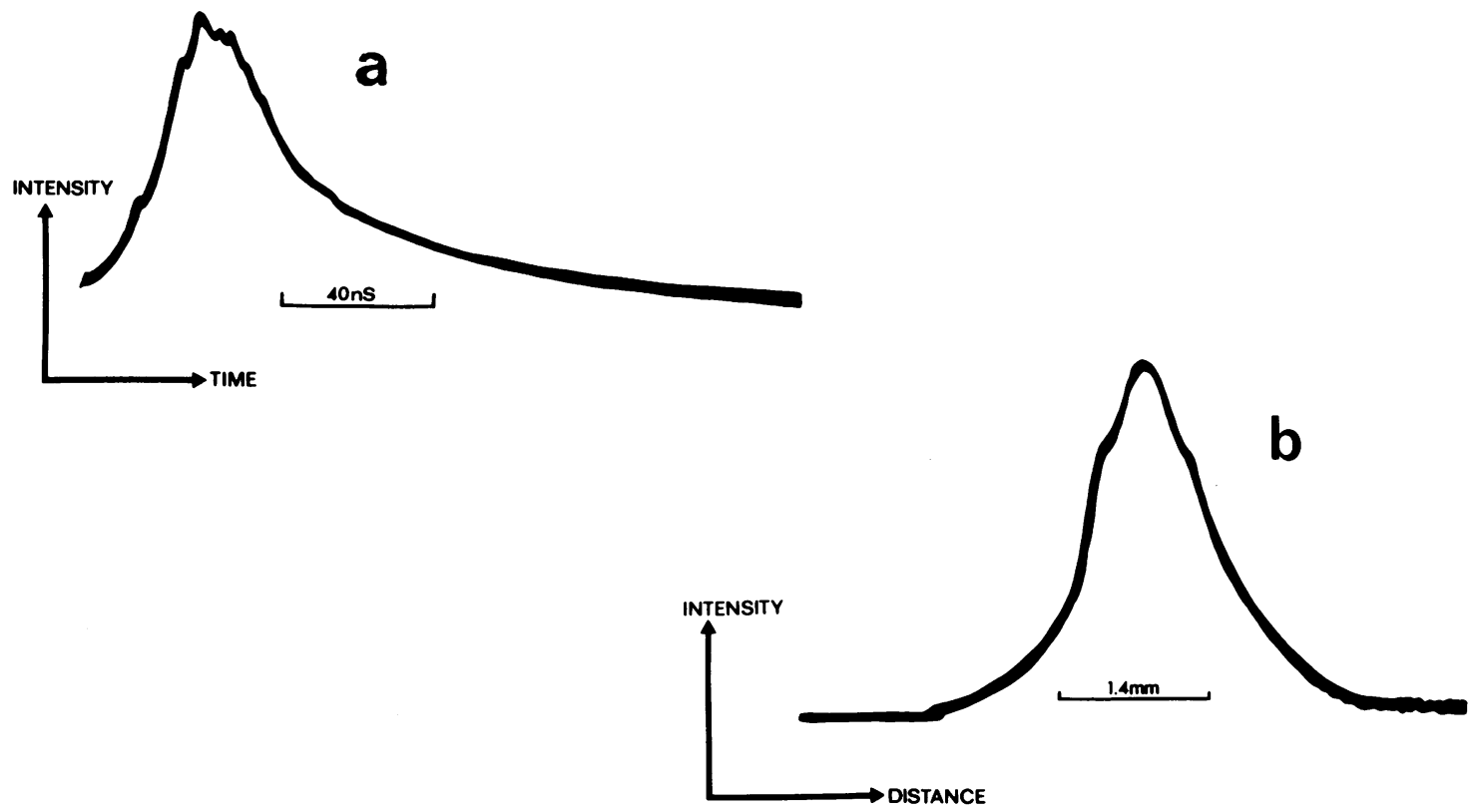

Fig. 1 Temporal (a) and spatial (b) intensity profiles recorded from typical Q-switched $N d / Y A G$ pulses.

variability in the pattern of the intensity from one pulse to another is minimised. The mode pattern of the unfocused neodymium/YAG beam was periodically recorded with a photodiode array detector (EG and G Reticon RL512G) so that adjustments could be made to the laser cavity optics, if necessary, to regain the fundamental mode (indicated by a smooth Gaussian profile). This also permitted measurements of beam diameter to be made. ${ }^{*}$ The spatial intensity profile of a typical pulse, as recorded by the array, is shown in Fig. 1b.

The experimental arrangement used for these

*The laser beam diameter entering the beam expanding telescope was $1.5 \mathrm{~mm}$, the diameter leaving it was $9.0 \mathrm{~mm}$, and the converging angle of the beam leaving the final focusing lens was $6^{\circ}$. The estimated power density over the focal spot, which was below $50 \mu \mathrm{m}$ in diameter, was of the order of $10^{8} \mathrm{Watt} / \mathrm{mm}^{2}$. studies is shown in Fig. 2 A low-power continuous wave helium neon laser beam was directed coaxially into the invisible $\mathrm{Nd} / \mathrm{YAG}$ beam to mark its path and allow visual focusing. The delivery system supplied with the Nd/YAG laser was removed, and the two beams were delivered to the target through a beam expanding telescope and a single focusing lens. A beam splitter was positioned to reflect all of the $\mathrm{Nd} / \mathrm{YAG}$ beam and a proportion of the $\mathrm{HeNe}$ beam through $90^{\circ}$ while allowing the through passage of visible light for observations via an operating microscope.

The focusing lens was mounted on a micropositioning stage so that its position along the axis of the beams could be altered and set with precision. This set the position at which the HeNe beam was focused relative to the surface of the target. Since it is
Fig. 2 Schematic diagram of experimental apparatus.

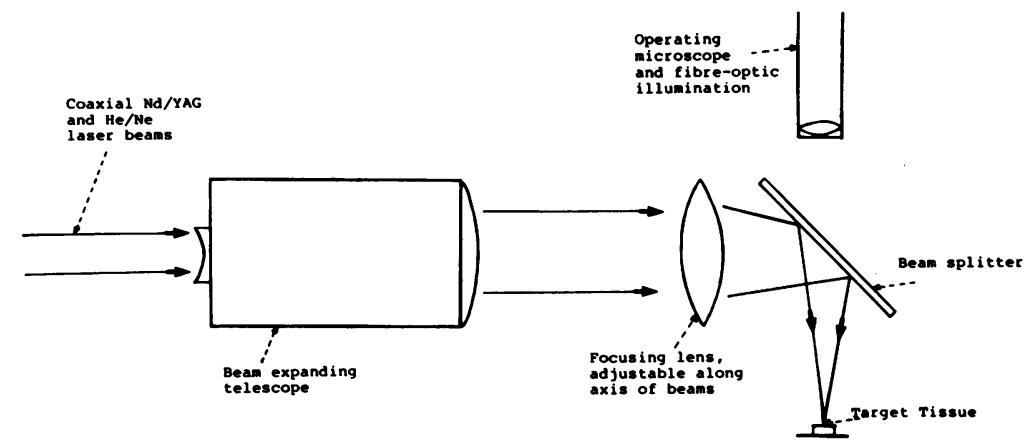


theoretically likely that the Nd/YAG focal point would not exactly coincide with that of the $\mathrm{HeNe}$ beam, many of the $\mathrm{Nd} / \mathrm{YAG}$ pulses were fired with the $\mathrm{HeNe}$ focus at points other than the target surface - that is, up to $4 \mathrm{~mm}$ beyond the surface of the tissue and $2 \mathrm{~mm}$ in front of it.

The laser pumping voltage, which determined the pulse energy, was set at $750 \mathrm{~V}$ for all the pulses fired in this study. The actual pulse energy output was measured with a photodiode-based energy monitor (J K Lasers Ltd) and was in the range $30.0 \mathrm{~mJ}$ to $32.4 \mathrm{~mJ}$, corresponding to pulse power of the order of $10^{6}$ Watts. One, two, or three pulses were fired at each target site, allowing at least $10 \mathrm{~s}$ to elapse between pulses. The details are shown in Table 1 .

\section{TISSUE}

Wedges of tissue comprising the outflow system and the limbal regions of cornea, anterior sclera, iris, and ciliary body were dissected from the excised anterior segments of five enucleated human eyes. Human tissue was preferred because of its distinctive morphology vis-à-vis that of other primates. Details of the age of the donor, and the treatment of the tissue are given in Table 2, but, to summarise, most of the tissue was obtained post mortem from elderly donors, approximately half the material was fixed in glutaraldehyde before laser treatment, and the rest was fixed immediately after laser treatment. All the tissue was kept wet until immediately before laser treatment to minimise drying artefacts. The scleral base of each tissue wedge was glued to a small metal block, and the uveal surface of the meshwork was exposed to the Q-switched Nd/YAG pulses.

MORPHOLOGICAL METHODS

The first stage of the morphological study of the

Table 1 Conditions of laser treatment and corresponding effects

\begin{tabular}{|c|c|c|c|c|c|}
\hline $\begin{array}{l}\text { Code } \\
\text { No. of } \\
\text { eye }\end{array}$ & $\begin{array}{l}\text { Tissue } \\
\text { state }\end{array}$ & $\begin{array}{l}\text { No. of } \\
\text { sites } \\
\text { treat- } \\
\text { ment }\end{array}$ & $\begin{array}{l}\text { No. of } \\
\text { pulses } \\
\text { persite }\end{array}$ & $\begin{array}{l}\text { No. of } \\
\text { holes } \\
\text { made }\end{array}$ & $\begin{array}{l}\text { Range of positions beyond } \\
\text { (b) or in front of }(f) \text { the } \\
\text { HeNe focus for which holes } \\
\text { were made }\end{array}$ \\
\hline 1 & Fixed & 20 & 1 & 17 & $3 \mathrm{~mm}$ b to $0.5 \mathrm{~mm} \mathrm{f}$ \\
\hline 1 & Fixed & 6 & 2 & 4 & $3 \mathrm{~mm} \mathrm{~b}$ to $0.5 \mathrm{~mm} \mathrm{f}$ \\
\hline 1 & Fixed & 1 & 3 & 1 & $1 \mathrm{~mm} \mathrm{~b}$ \\
\hline 2 & Fixed & 6 & 1 & 2 & $3 \mathrm{~mm} b$ to $\mathrm{HeNe}$ focus \\
\hline 3 & Fixed & 1 & 1 & 1 & At $\mathrm{HeNe}$ focus \\
\hline 3 & Fixed & 5 & 2 & 3 & $1 \mathrm{~mm} \mathrm{~b}$ to $\mathrm{HeNe}$ focus \\
\hline 4 & Fresh & 5 & 1 & 2 & $1 \mathrm{~mm} \mathrm{~b}$ to $\mathrm{HeNe}$ focus \\
\hline 4 & Fresh & 6 & 2 & 3 & $2 \mathrm{~mm} \mathrm{~b}$ to $1 \mathrm{~mm} \mathrm{~b}$ \\
\hline 5 & Fresh & 4 & 1 & 3 & $0.6 \mathrm{~mm}$ b to $0.5 \mathrm{~mm} \mathrm{~b}$ \\
\hline 5 & Fresh & 11 & 2 & 6 & $0.6 \mathrm{~mm} \mathrm{~b}$ to $0.25 \mathrm{~mm} \mathrm{~b}$ \\
\hline 3 & Fresh & 1 & 1 & 0 & - \\
\hline 3 & Fresh & 12 & 2 & 8 & $1.5 \mathrm{~mm} \mathrm{~b}$ to $\mathrm{HeNe}$ focus \\
\hline
\end{tabular}

effects of the laser pulses on the tissue was scanning electron microscopy (Jeol JSM T200), for which the samples were prepared by critical point drying. Measurements of the areas of meshwork surface visibly damaged by the laser were made by image analysis (Micro Measurement Ltd, Optomax).

Some of the specimens that showed clear laser holes by scanning electron microscopy were then reprocessed for resin embedding by transfer through amyl acetate, ethanol, and a 50/50 mix of propylene oxide and resin (either Araldite or Transmit). Semithin $(1 \mu \mathrm{m})$ serial sections were cut and stained with toluidine blue for light microscopy. Measurements of the maximum diameter of each hole were made from photomicrographs at known magnifications. Ultrathin sections $(60-80 \mathrm{~mm})$ were cut from selected specimens, stained with uranyl acetate and lead citrate, and studied by transmission electron microscopy (Philips EM301).

\section{Results}

Table 1 summarises the results in terms of the laser holes made in each tissue sample under different operating conditions. It was found that $30 \mathrm{~mJ}$ pulses could make clearly defined holes in both fixed and fresh trabecular tissue. Holes could be made in fixed tissue when the tissue surface was positioned anywhere between $1 \mathrm{~mm}$ in front of the plane of focus for the helium neon beam and $3 \mathrm{~mm}$ beyond it. Determining the focus of the HeNe beam on the meshwork surface was found to be much more difficult for fresh tissue than for fixed, probably because the fresh tissue was so transparent that very little light was scattered back from its surface. It should be noted that this might be ultimately a problem in vivo, in the clinical application of this laser treatment. However,

Table 2 Source and treatment of tissue

\begin{tabular}{|c|c|c|}
\hline $\begin{array}{l}\text { Code number } \\
\text { of eye }\end{array}$ & $\begin{array}{l}\text { Age of donor } \\
\text { (years) }\end{array}$ & Treatment of tissue \\
\hline 1 & 64 & $\begin{array}{l}\text { Eye enucleated post mortem and } \\
\text { fixed in glutaraldehyde }\end{array}$ \\
\hline 2 & 64 & $\begin{array}{l}\text { Eye enucleated post mortem and } \\
\text { fixed in glutaraldehyde }\end{array}$ \\
\hline 3 & Over 60 & $\begin{array}{l}\text { Eye enucleated post mortem, half } \\
\text { fixed in glutaraldehyde, and half } \\
\text { laser treated unfixed within } 3 \\
\text { hours }\end{array}$ \\
\hline 4 & 70 & $\begin{array}{l}\text { Eye enucleated post mortem and } \\
\text { laser treated unfixed within } 3 \\
\text { hours }\end{array}$ \\
\hline 5 & 76 & $\begin{array}{l}\text { Eye enucleated from living donor } \\
\text { (because of choroidal melanoma) } \\
\text { and laser treated unfixed within } \\
11 / 2 \text { hours }\end{array}$ \\
\hline
\end{tabular}




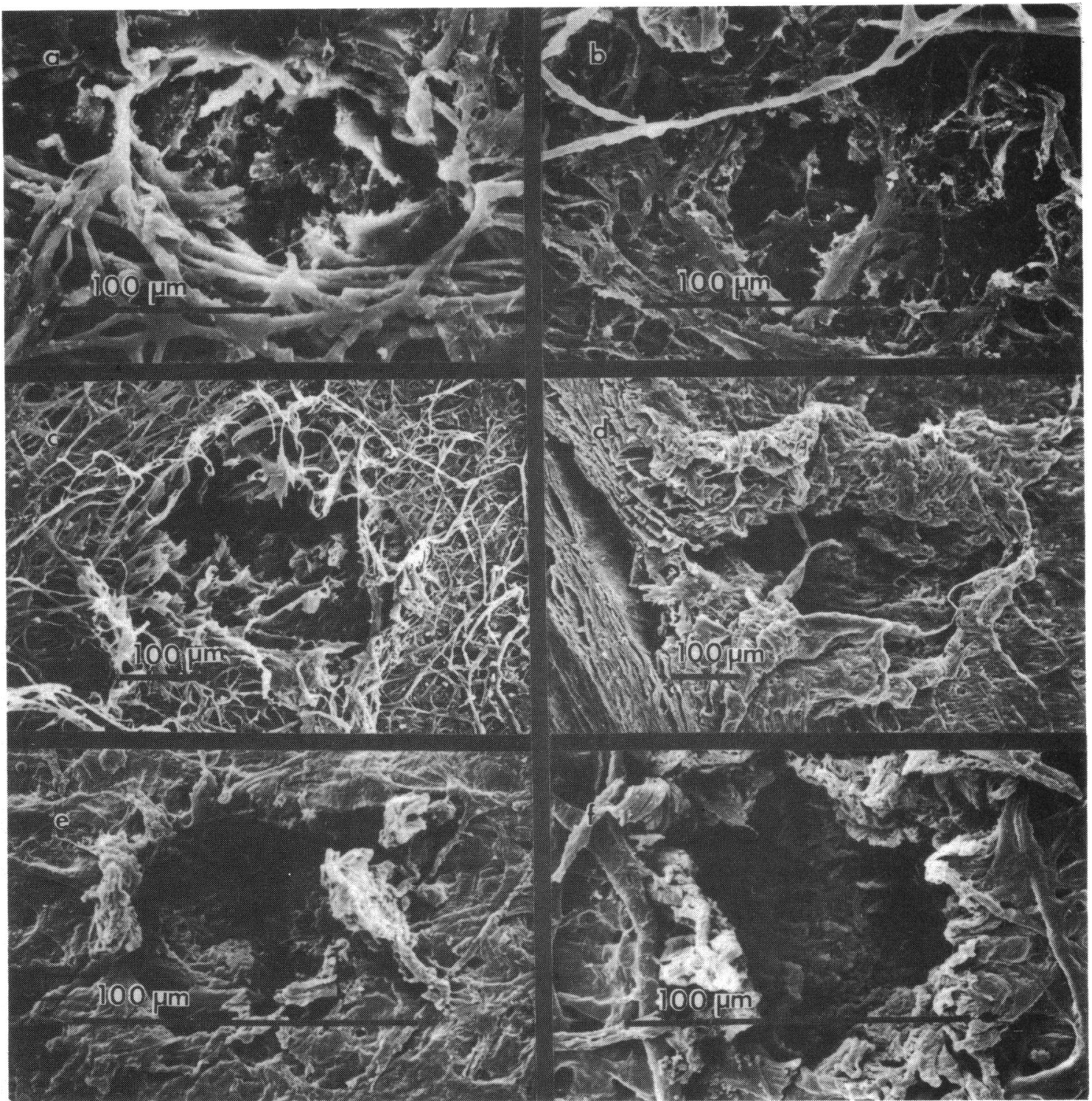

Fig. 3 Scanning electron micrographs of laser holes, made under the following conditions: (a) 2 pulses into fresh tissue at $1.0 \mathrm{~mm}$ beyond the HeNe focus; (b) 2 pulses into fresh tissue at $0.25 \mathrm{~mm}$ beyond the HeNe focus; (c) 2 pulses into fresh tissue at $0.60 \mathrm{~mm}$ beyond the HeNe focus; (d) 2 pulses into fresh tissue at $0.30 \mathrm{~mm}$ beyond the HeNe focus; (e) 1 pulse into fresh tissue at $1.0 \mathrm{~mm}$ beyond the HeNe focus; (f) 2 pulses into fresh tissue at $0.5 \mathrm{~mm}$ beyond the HeNe focus.

in the present investigation it was found that the effective depth of focus for fresh tissue was approximately half that for fixed tissues.

Scanning electron micrographs of a selection of the laser holes are shown in Fig. 3. Each hole, in fixed or fresh tissue, was sharply outlined by truncated trabecular beams and sometimes by a folded-back rim of tissue. This morphology could be interpreted as an effect of concentrated explosions at or just below the surface. There was considerable variation in the size of the holes. The morphometric studies (image analysis) showed that $75 \%$ of the holes made had areas in the range 1500 to $15000(\mu \mathrm{m})^{2}$. There was no significant correlation between the internal area of the hole and two variables of the laser delivery system-the tissue position relative to the $\mathrm{HeNe}$ 

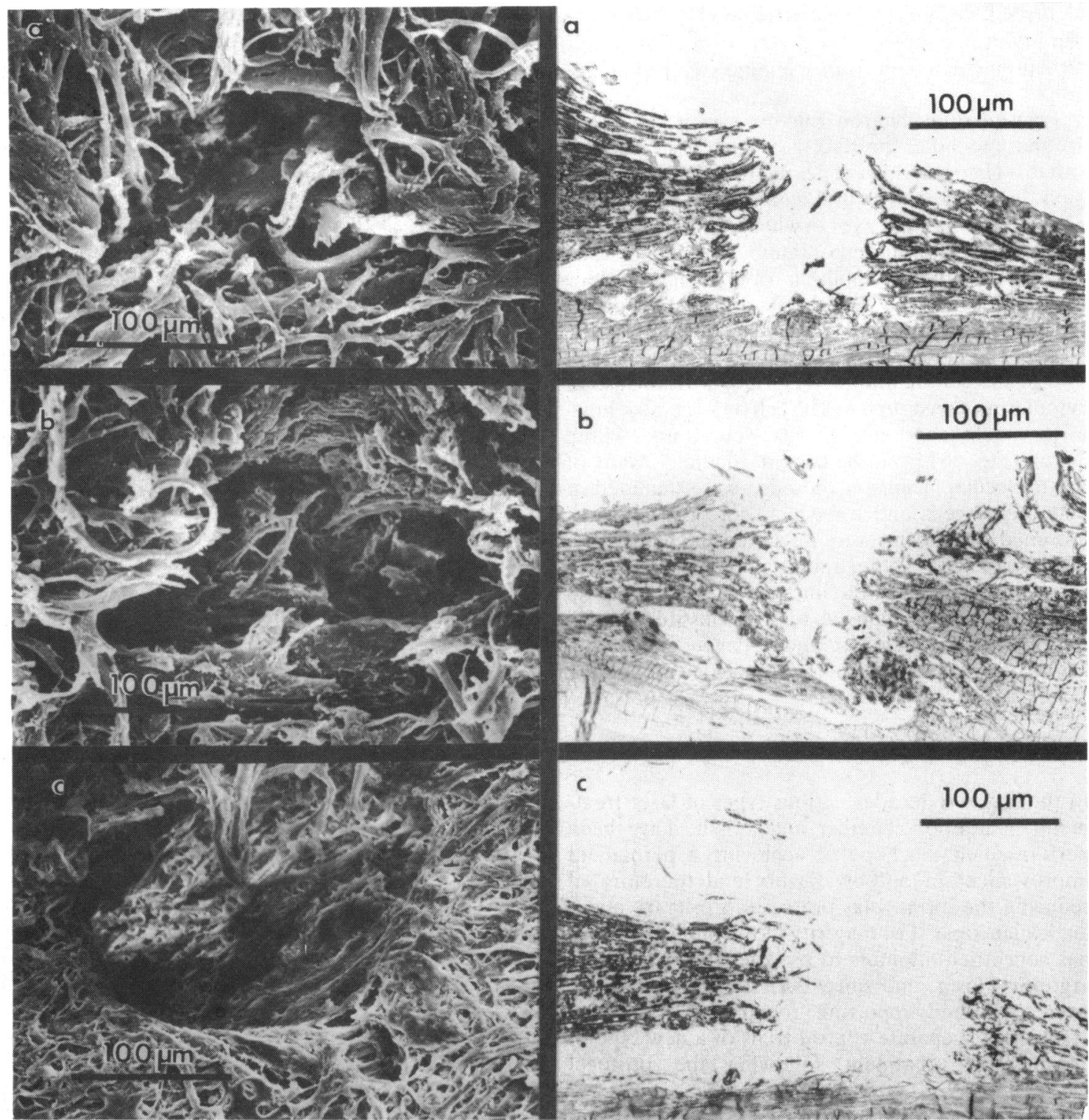

Fig. 4 Scanning electron micrographs and photomicrographs of three laser holes made under the following conditions:

(a) 2 pulses into fresh tissue at $2.0 \mathrm{~mm}$ beyond the $\mathrm{HeNe}$ focus; (b) 1 pulse into fresh tissue positioned at the HeNe focus;

(c) 1 pulse into fresh tissue at $0.5 \mathrm{~mm}$ beyond the $\mathrm{HeNe}$ focus.

focus, and the number of pulses fired per site. Even the holes created under apparently identical conditions varied considerably. For example, three holes made in fixed tissue from the same eye, positioned $1 \mathrm{~mm}$ beyond the $\mathrm{HeNe}$ focus, and receiving a single pulse at each site, had areas of 3360,4100 and $11300(\mu \mathrm{m})^{2}$ respectively.

Light microscopy of tissue sections stained with toluidine blue showed that many of the holes made by laser pulses extended through the full thickness of trabecular meshwork into Schlemm's canal. This was often not obvious by scanning electron microscopy, even by examination of stereopairs of micrographs in a stereoviewer. Fig. 4 shows corresponding pairs of scanning electron micrographs and light micrographs of three of the lasered specimens. The clean-cut edges of the laser holes are also more obvious in the photographs of the $1 \mu \mathrm{m}$ tissue sections. Measure- 
ments of hole diameter taken from such photographs were typically approximately $80 \%$ of corresponding measurements taken from scanning electron micrographs.

Transmission electron microscopy of the tissue around the holes produced by the laser showed variable changes which appeared to be dependent on both the induced structural damage and on the state of autolysis. In those eyes in which cellular preservation could be considered optimum (specimens 1 and 5 ) it was possible to establish normal cell morphology at distances between 50 and $200 \mu \mathrm{m}$ from the edge of the hole (Fig. 5 and 6). Within 50 to $100 \mu \mathrm{m}$ from the edge of the hole some cells showed obvious disruption of the cell membrane (Fig. 5b) with release of cytoplasmic constituents. The cell damage was, however, patchy, and intact cells were found within $35 \mu \mathrm{m}$ (Fig. 6b) from the edge of the hole. Many of the trabecular beams at the edge were denuded of endothelial cells and trabecular core material was loosened. The beams were disrupted and bent over a distance of about $25 \mu \mathrm{m}$ and fragments of trabecular cores were present in the interspaces. There was no apparent thermal damage to the constituents, for example, basement membrane, collagen, and elasticlike tissues, of the cores of the trabeculae around the hole.

\section{Discussion}

In the last two decades various types of laser treatment of anterior chamber angle tissue have been performed in the hope of achieving a permanent improvement in outflow facility and therefore of reducing the intraocular pressure in primary openangle glaucoma. The majority of the published work has concerned attempts to use the widely available argon ion laser, and since 1981 four papers ${ }^{2-5}$ have been published reporting remarkably consistent results from separate clinical trials of a new type of argon laser treatment following the protocol described by Wise et al in $1979 .{ }^{6}$

The long-term effectiveness of argon laser trabeculoplasty (ALT) has not yet been fully established, but in the short term reduced resistance to aqueous outflow seems to be due to the laser energy absorbed by the tissue acting thermally to shrink the meshwork at the site of each burn and so stretch the tissue between burns, opening up the intertrabecular spaces. This possible mechanism has not yet been fully investigated pathologically, but one SEM study of the effects of $\mathrm{ALT}^{7}$ has described fibrinous material and necrosis immediately after laser treatment, followed by a gradual occlusion of the intertrabecular spaces by migrating endothelial cells. A cellular reaction of this nature, combined with reactionary
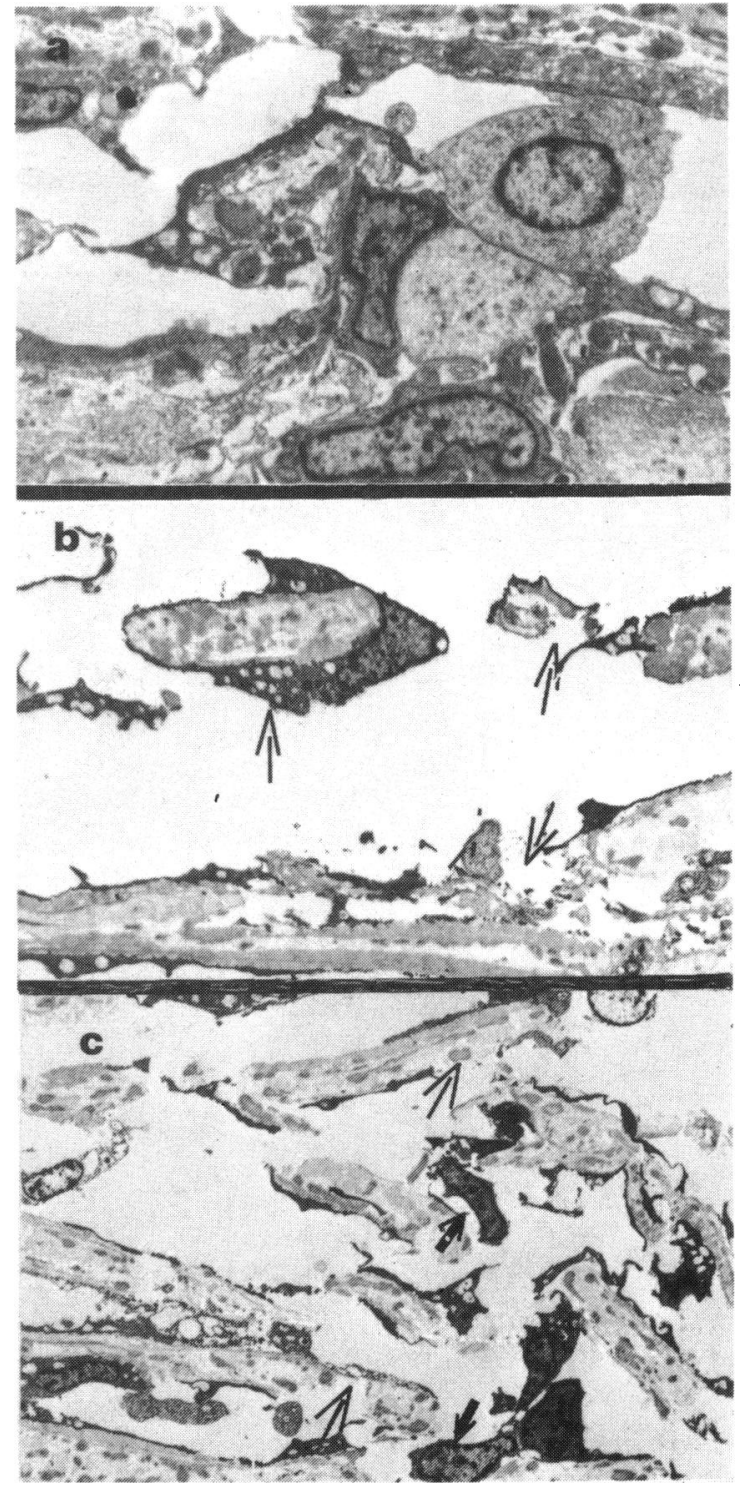

Fig. 5 Transmission electron micrographs of a laser hole made in fixed tissue by a single $31.2 \mathrm{~mJ}$ pulse at the HeNe focus (case 1): (a) the outer meshwork 200 um from the edge of the hole - the morphology is within normal limits ( $\times 3500)$; (b) the uveal meshwork, 80 um from the edge-the endothelial cells show cytoplasmic disruption $(\times 2000)$; (c) The edge of the laser hole in the uveal meshwork-distorted and fragmented trabecular cores are in parts lined by disrupted endothelial cells (thin arrows) and occasionally by intact cells (thick arrows) $(\times 1640)$.

fibrosis, could in theory cause a reduction of the outflow facility in the long term.

Q-switched laser pulses are quite different from 


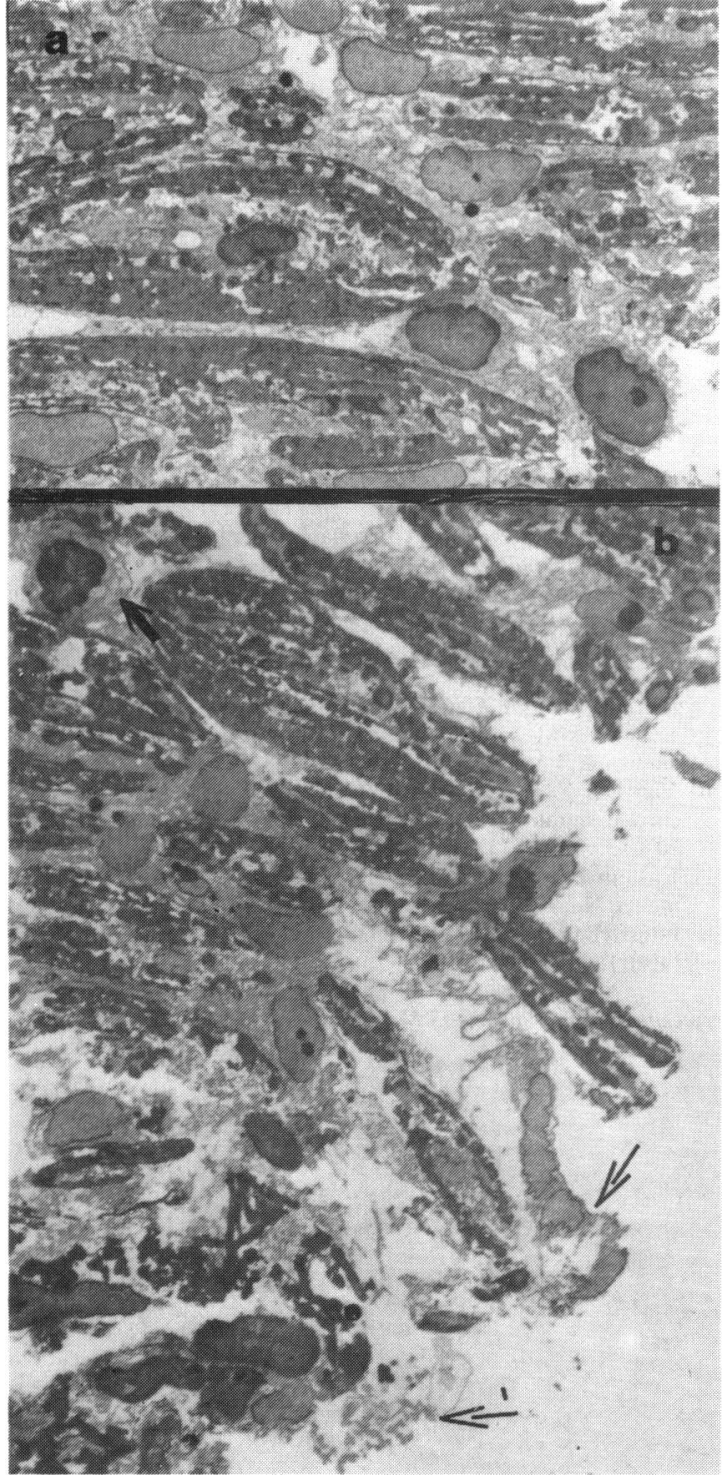

Fig. 6 Transmission electron micrographs of a laser hole made in unfixed tissue by a single $30.6 \mathrm{~mJ}$ pulse at $0.5 \mathrm{~mm}$ beyond the HeNe focus (case 5): (a) the outer meshwork 30 um from the edge of the hole shows autolytic cytoplasmic vacuolation only $(\times 2000)$; (b) at the edge of the hole the trabeculae are fractured and the cells are ruptured (thin arrows); intact cells (thick arrow) are present within 30 um of the edge $(\times 2000)$.

the output of continuous wave lasers in that they are several orders of magnitude greater in power, though low in energy. A typical neodymium/YAG laser, for example, could yield a Q-switched pulse of a few tens of millijoules but with a pulse duration so short that the power delivered during the pulse is one million times that of a typical $0 \cdot 1 \mathrm{~s}$ burst of argon laser radiation. Such high-power pulses, if sharply focused to give very high-power densities, cause damage by vapourising a very localised volume at their focus without raising the temperature of surrounding matter significantly. The destruction is caused by non-linear processes characteristic of very high electric fields rather than the more familiar chemical absorption, and so is largely independent of the colour of the target. $^{8}$

These properties of Q-switched pulses-the localised non-thermal damage, and the ability to act on transparent tissue-make them an attractive choice for laser trabeculotomy. As long ago as 1972 Krasnov ${ }^{9}$ reported promising results using Qswitched pulses from a ruby laser to create large holes through meshwork into Schlemm's canal. Although it was effective in reducing the IOP in the short term, long-term follow-up showed a decline in the effectiveness of this technique in maintaining a reduced level of IOP, and it has not been generally adopted. Neodymium/YAG and neodymium/glass lasers have been used experimentally with some success, but clinical attempts to perform either laser trabeculotomies or cyclodialyses have been disappointing,${ }^{10}$ posibly because of induced collapse of Schlemm's canal and closure of the laser opening respectively.

The in-vitro application of a well characterised and controlled YAG laser system to human tissue was considered to be essential for the study of the basic configurational features of laser induced trabeculotomies. The result of laser treatment in our experiments, as shown by light microscopy and scanning electron microscopy, was a series of tiny holes of roughly rounded cross section and generally extending into Schlemm's canal irrespective of the intrinsic thickness of the trabecular tissue. This suggests that the explosive force of the focused laser pulse was somewhat dissipated by the presence of the canal; it is interesting to note that any damage to the outer wall of the canal was well localised and superficial.

An interesting feature of our investigation is that no simple correlation was found between the dimensions of the laser-induced hole and the laser operating parameters within the chosen range. Various factors such as higher reflectivity made focusing more difficult for fresh tissue than for fixed, but in all cases there was considerable variability in the intrinsic architecture of the tissue, the extent of aging changes such as trabecular thickening and deposition of curly collagen, and the degree of autolysis before fixation. This variability may have masked any underlying pattern of dimensional dependence on pulse number or degree of defocusing.

It was not possible to approach the clinical in-vivo 
situation in these experiments even with a freshly enucleated eye because of the degree of unavoidable autolysis that occurred while transporting the tissue to the laboratory and optimising the laser system's parameters just prior to use. We cannot really comment on any short- or long-term damage which a YAG system of this type might induce in endothelial cells around the site of a focused pulse in vivo. However, the results obtained from the TEM study of selected holes indicated that endothelial cells had an apparently undisturbed morphology outside a range of approximately $100 \mu \mathrm{m}$. In the best preserved fresh tissue (case 5) intact cells were found within $30 \mu \mathrm{m}$ of the edge of the hole, and this raises the possibility that endothelial cell cover could be restored after in vivo laser treatment. Fragmentation of the trabecular cores was limited to a narrow band of approximately 20 to $30 \mu \mathrm{m}$ from the edge of the hole, and it seems unlikely that, in vivo, liberated core materials would produce significant secondary obstruction to the canal. The most important problems still to be resolved in the use of the YAG laser to perform trabeculotomies are the subsequent repair response of the trabecular tissue and any unforeseen effects on other constituents of the anterior chamber in vivo. To our knowledge such information is not yet available, but preliminary primate experimental studies have yielded somewhat disappointing results."
This study was supported by the Rank Prize Fund (grant no. 7269).

\section{References}

1 Venkatesh S, Guthrie S, Foulds, WS, Lee WR, Cruickshank FR, Bailey RT. In vitro studies with a pulsed neodynium/YAG laser. Br J Ophthalmol 1985; 69: 86-91.

2 Wise JB. Long-term control of adult open angle glaucoma by argon laser treatment. Ophthalmology (Rochester) 1981; 88: 197-202.

3 Schwartz AL, Whitten ME, Bleiman B, Martin D. Argon laser trabecular surgery in uncontrolled phakic open angle glaucoma. Ophthalmology (Rochester) 1981; 88: 203-12.

4 Wilensky JT, Jampol LM. Laser therapy for open angle glaucoma. Ophthalmology (Rochester) 1981; 88: 213-7.

5 Pohjanpelto $\mathrm{P}$. Argon laser treatment of the anterior chamber angle for increased intraocular pressure. Acta Ophthalmol (Kbh) 1981; 59: 211-20.

6 Wise JB, Witter SL. Argon laser therapy for open angle glaucoma: a pilot study. Arch Ophthalmol 1979; 97: 319-22.

7 Rodrigues MM, Spaeth GL, Donohoo P. Electron microscopy of argon laser therapy in phakic open angle glaucoma. Ophthalmology (Rochester) 1982; 89: 198-210.

8 Bloembergen $\mathrm{N}$. Laser-induced electric breakdown in solids. IEEE J Quantum Electrodynamics 1974; QE-10: 375-86.

$9 \mathrm{Krasnov}$ MM. Laser puncture of the anterior chamber angle in glaucoma. Vestn Oftalmol 1972; 3: 27-31.

10 Van Der Zypen E, Fankhauser F. Lasers in the treatment of chronic simple glaucoma. Trans Ophthalmol Soc UK 1982; 102: 147-53.

11 Epstein DL, Melamed S, Puliafito CA, Steinert RF. Experimental Nd:YAG trabeculopuncture in the monkey: potential for future clinical use. J Am Acad Opththalmol 1984; 91 (suppl 77): 9 (abstr).

Accepted for publication 13 May 1985. 